OPEN ACCESS

Edited by:

Marcelo Menossi Menossi, Universidade Estadual de Campinas,

Brazi

Reviewed by:

Khurram Bashir,

Riken Brain Science Institute, Japan

Biswapriya Biswavas Misra,

University of Florida, USA

*Correspondence: Filiz Güre filiz@istanbul.edu.tr

Specialty section: This article was submitted to

Plant Biotechnology,

a section of the journal Frontiers in Plant Science

Received: 22 February 2016 Accepted: 18 July 2016 Published: 03 August 2016

Citation:

Gürel F, Öztürk ZN, Uçarlı C and Rosellini D (2016) Barley Genes as Tools to Confer Abiotic Stress Tolerance in Crops.

Front. Plant Sci. 7:1137. doi: 10.3389/fpls.2016.01137

\section{Barley Genes as Tools to Confer Abiotic Stress Tolerance in Crops}

\author{
Filiz Gürel ${ }^{1 *}$, Zahide N. Öztürk ${ }^{2}$, Cüneyt Uçarlı ${ }^{1}$ and Daniele Rosellini ${ }^{3}$ \\ ${ }^{1}$ Department of Molecular Biology and Genetics, Faculty of Science, Istanbul University, Istanbul, Turkey, ${ }^{2}$ Department of \\ Agricultural Genetic Engineering, Ayhan Şahenk Faculty of Agricultural Sciences and Technologies, Niğde University, Niğde, \\ Turkey, ${ }^{3}$ Department of Agricultural, Food, and Environmental Sciences, University of Perugia, Perugia, Italy
}

Barley is one of the oldest cultivated crops in the world with a high adaptive capacity. The natural tolerance of barley to stress has led to increasing interest in identification of stress responsive genes through small/large-scale omics studies, comparative genomics, and overexpression of some of these genes by genetic transformation. Two major categories of proteins involved in stress tolerance are transcription factors (TFs) responsible from the re-programming of the metabolism in stress environment, and genes encoding Late Embryogenesis Abundant (LEA) proteins, antioxidant enzymes, osmolytes, and transporters. Constitutive overexpression of several barley TFs, such as C-repeat binding factors (HvCBF4), dehydration-responsive element-binding factors (HvDREB1), and WRKYS (HVWRKY38), in transgenic plants resulted in higher tolerance to drought and salinity, possibly by effectively altering the expression levels of stress tolerance genes due to their higher DNA binding affinity. $\mathrm{Na}^{+} / \mathrm{H}^{+}$antiporters, channel proteins, and lipid transporters can also be the strong candidates for engineering plants for tolerance to salinity and low temperatures.

Keywords: drought, Hordeum vulgare, LEA proteins, salinity, transcription factors

\section{INTRODUCTION}

Drought, salinity, high or low temperatures, frost, flooding, alkaline soil, and excess or deficiency of minerals like boron and aluminum can have significant adverse effects on agricultural production (Atkinson and Urwin, 2012). Particularly, drought and soil salinity even threat plant biodiversity in arid and semi-arid regions.

Plants have various protective mechanisms for coping with abiotic stress conditions. Both mechanisms based on single genes and complex regulatory pathways involved in stress tolerance and/or adaptation have been described in plants, and partially resolved by omics approaches of system biology (Gupta et al., 2013). Knowledge of the molecular basis of stress tolerance and adaptation is essential to develop crop cultivars with improved stress tolerance.

Barley (Hordeum vulgare L.) is one of the oldest cereal crops known to be cultivated since about 10,000 years in a region located between the Nile (Egypt) and Tigris Rivers (Iraq), also including Southern Turkey, Israel, Lebanon, Jordan, and Syria. It has a natural tolerance to drought, salinity, and fungal diseases, thus making it a model organism in stress biology research. Indeed, a barley plant was shown to complete its life-cycle before using all the available soil water, even in high salt concentrations and defined as the most salt-tolerant cereal (Munns et al., 2006).

Substantial work has been done to map genetic determinants controlling abiotic stress tolerance, which was the object of QTLs, meta-analysis that indicated the importance of $2 \mathrm{H}$ and $5 \mathrm{H}$ chromosomes (Li et al., 2013). In addition, molecular responses to drought, salinity, boron toxicity, 
cold acclimation, and high temperature have been revealed by high-throughput transcriptomic analyses (Ozturk et al., 2002; Svensson et al., 2006; Guo et al., 2009; Mangelsen et al., 2011; Tombuloglu et al., 2013; Bedada et al., 2014). Transcriptomic approaches have provided a large amount of data that enable researchers to identify major pathways and key proteins contributing to stress tolerance in barley. These major pathways are controlled by partially overlapping signaling components including abscisic acid (ABA), salicylic acid (SA), and jasmonic acid (JA). Major alterations have been detected in protein biosynthesis, energy metabolism, photosynthesis, protein folding, detoxification, and cell wall biosynthesis during the stress response of barley (Sicher et al., 2012; Rollins et al., 2013).

The wealth of knowledge gathered on barley genetics, genomics, diversity, genetic transformation, and stress responses makes this crop a platform for dissecting tolerance mechanism that can be then exploited in other crops, particularly cereals. Despite the complex nature of abiotic stress tolerance, single genes from barley can have potential in biotechnological crop improvement. In this minireview, our aim is to highlight notable genes from barley that may be used to improve plants for abiotic stress tolerance, with an emphasis on TFs.

\section{Overview of Stress Adaptation Genes in Barley}

Barley can cope with many abiotic stress factors, single or combined, and several genes involved have been identified (Figure 1). One of the factors behind the natural tolerance of barley to abiotic stresses is early flowering, which ensures that pollination, seed development, and maturation occur in an optimum time period. Major genes affecting flowering time in barley have been identified and shown to be mainly related with vernalization, photoperiod, and circadian clock (Turner et al., 2005; von Zitzewitz et al., 2011). For example, $H v C E N$ and $H v L u x 1$ control flowering time, while the circadian clock gene $P p d-H 1$ regulates photoperiodrelated output genes (Campoli et al., 2012; Comadran et al., 2012).

Expression of antioxidant enzymes such as HvAPX1, HvMT-2, and $H v G S T 1$, accumulation of osmolytes and synthesis of heatshock proteins (e.g., HSP17.8) are among the initial responses to stress mainly generated by reactive oxygen species (ROS; Guo et al., 2009; Witzel et al., 2009). By the induction of transcription factors including $M Y B, H v D R F 1, H v D R E B, H v A B F 1$, barley responds to stress with a large, partially elucidated network of genes. For instance, the expression of $\mathrm{H} v \mathrm{CBF}$ genes at the $\mathrm{Fr}-\mathrm{H} 2$ locus, which is controlled by a vernalisation TF gene, VRN-H1, affects frost tolerance (Stockinger et al., 2007).

A group of genes, HVA1, HVA22, Dhn3, and Dhn9 encode proteins that bind to membrane phospholipids, ions and water, and protect cells by still unknown mechanisms. Overexpression of $\mathrm{Na}$ transporters $(H v H K T 2 ; 1)$ were shown to contribute to the regulation of $\mathrm{Na}^{+} / \mathrm{K}^{+}$homeostasis in barley during high salinity stress (Mian et al., 2011). In fact, $\mathrm{K}^{+}$retention ability and limitation of $\mathrm{Na}^{+}$uptake partially explains the tolerance of barley to ion toxicity and high salinity (Adem et al., 2014).

\section{Transcription Factors: Key Players for Stress Tolerance}

Engineering the regulatory machinery through transcription factors controlling the expression of stress-related genes is a promising approach to increase abiotic stress tolerance. Many transcription factors including DREB/CBF, ABF, AP2/ERF, bZIP, NAC, MYB, MYC, HD-ZIP, bHLH, NF-Y, EAR, and WRKY are known to be responsible for transcriptional reprogramming in response to abiotic stress conditions in plants. Several of these transcription factors have been cloned and characterized both at the genomic and protein levels in barley, and functionally proven to be useful for engineering stress tolerance in transgenic plants (Table 1).

The effectiveness of a TF in regulating many genes at a time is determined by its affinity to specific DNA sequences and its binding capacity to the promoter. Most of the promoter binding sites of barley TFs have been characterized (Table 1), and subtle changes in these motifs recently appeared to be important in determination of the binding affinity of TFs (Singh and Laxmi, 2015). As the natural ability of barley in coping with many abiotic stress factors suggests better DNA-binding specificity of TFs in transcriptional regulation of stress responsive genes, we believe barley TFs can be considered as promising candidates to increase abiotic stress tolerance of other crops.

WRKY TFs are a very large family of zinc finger TFs known to regulate temporal and spatial expression of specific genes during development and in response to environmental stimuli such as wounding, pathogen infection, or abiotic stresses. WRKY TFs have been studied in detail in numerous plant species including barley (Li et al., 2014). Constitutive expression of HvWRKY38 in bahiagrass (Paspalum notatum Flugge) caused better water retention capacity of transgenic plants during dehydration, and better recovery and rehydration with increased biomass production (Xiong et al., 2010).

DREB1/CBF and DREB2, induced by cold and dehydration in barley, respectively, belong to dehydration-responsive element binding protein/C-repeat binding factor family of TFs regulating expression of abiotic stress-related genes (Agarwal et al., 2006). An ortholog of the DREB1A TF isolated from a xeric, wild barley (H. spontaneum L.) under the transcriptional control of the stress-inducible HVA1 promoter was shown to enhance survival and biomass production upon severe salt stress and repeated cycles of severe dehydration stress in bahiagrass (James et al., 2008). Similarly, the overexpression of the HvDREB1 gene isolated from barley leaves increased salt stress tolerance in Arabidopsis (Xu et al., 2009).

The plant-specific NAC TFs are a major TF family with roles in regulation of several developmental programs and abiotic and biotic stress responsive genes (Nakashima et al., 2012; Puranik et al., 2012). The barley HvNAC6 gene acting as a regulator of basal resistance against the biotrophic pathogen Blumeria graminis f. sp. hordei, was shown to mediate ABA-dependent defense responses in barley (Chen et al., 2013). Overexpression of the isoform HvSNAC1 in barley increased drought tolerance (Al Abdallat et al., 2014), suggesting that this gene can be a tool for increasing barley productivity under drought conditions. A 


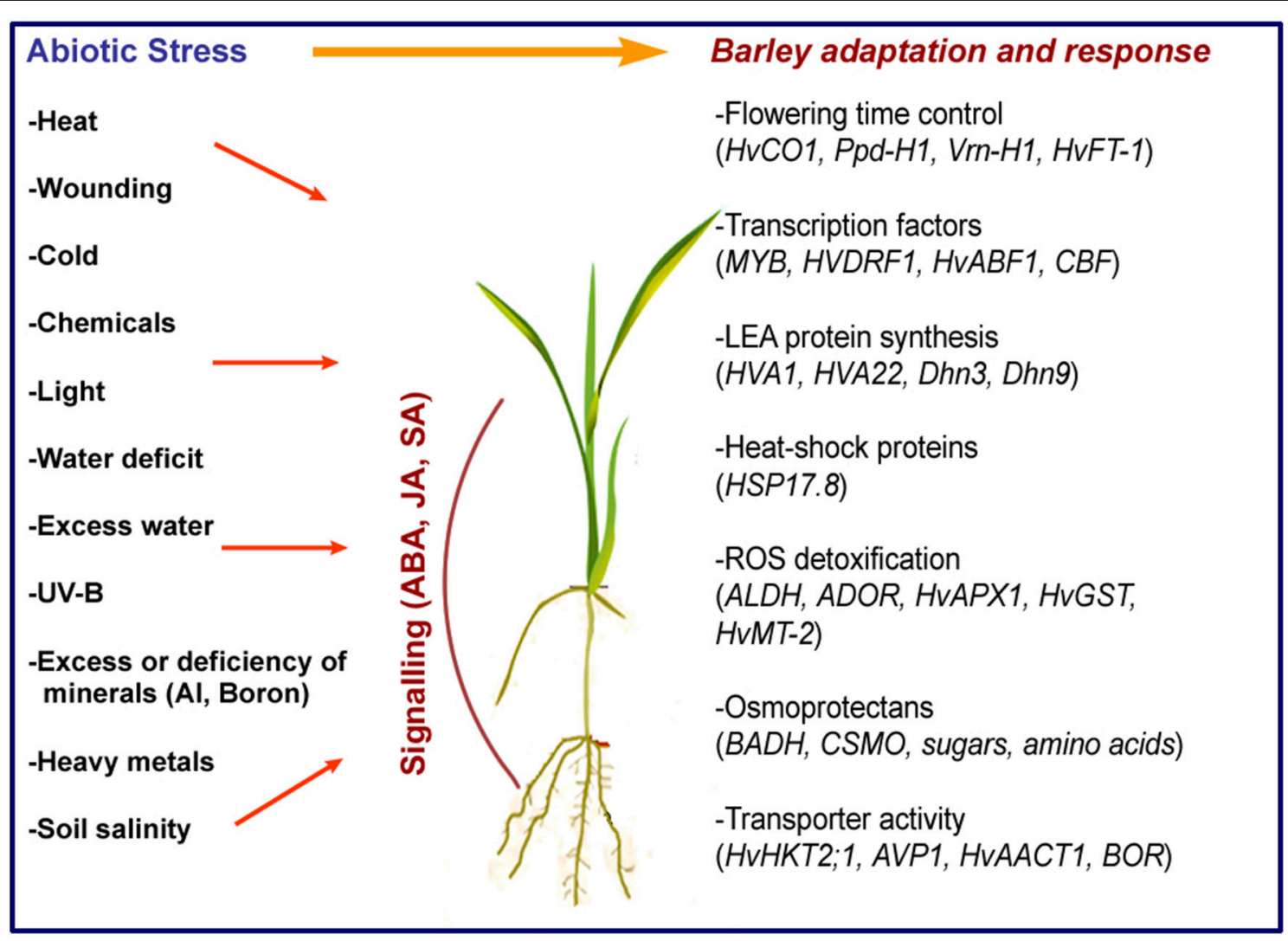

FIGURE 1 | Abiotic stress factors and main genes involved in adaptation and response in barley.

TABLE 1 | Features of stress-related transcription factors (TFs) cloned and characterized from barley and their use in transgenic approaches.

\begin{tabular}{|c|c|c|c|c|c|}
\hline $\begin{array}{l}\text { Barley transcription } \\
\text { factor }\end{array}$ & ABA-induction & $\begin{array}{l}\text { Binding site } \\
\text { (Cis-element) }\end{array}$ & $\begin{array}{l}\text { Use for transgenics/ } \\
\text { promoter }\end{array}$ & Tolerance to & References \\
\hline HVDRF1 & + & T(T/A)ACCGCCTT & No & Drought, salinity & Xue and Loveridge, 2004 \\
\hline $\mathrm{HvCBF} 4$ & - & CRT/DRE1/DRE2 & Yes/Ubi & Drought, salinity cold & Oh et al., 2007 \\
\hline HvDREB1 & - & DRE/CTE & Yes/CaMV $35 S$ & Salinity & Xu et al., 2009 \\
\hline HvDREB1A & nd & DRE/CTE & Yes/CaMV $35 S$ & Drought, salinity & James et al., 2008 \\
\hline HVRAF & - & GCC-box, CRT/DRE & Yes/CaMV $35 S$ & Salinity & Jung et al., 2007 \\
\hline HVSNAC1 & + & - & Yes/Ubi & Drought & Al Abdallat et al., 2014 \\
\hline HVWRKY38 & + & W-box[(T)(T)TGAC(C/T)] & Yes/CaMV $35 S$ & Dehydration & Xiong et al., 2010 \\
\hline
\end{tabular}

nd, not determined.

very recent study indicated the potential of overexpression of the same gene to enhance resistance of barley to Ramularia leaf spot (McGrann et al., 2015).

One of the earliest reports on isolation of a low-temperature induced AP2 domain and C-repeat/dehydration responsive element containing proteins identified HvCBF1 and HvCBF2, transcriptional activators of cold-responsive genes in barley (Xue, 2002, 2003). Indeed, CRF/DREBs mainly regulate freezing tolerance (Jeknić et al., 2014). Overexpression of $\mathrm{HvCBF4}$ in rice resulted in enhanced tolerance to drought, salt, and cold stresses at the seedling level (Oh et al., 2007).

HvRAF (barley root abundant factor), an ethylene response factor (ERF)-type TF, was shown to regulate transcriptional induction of various stress-responsive genes including PDF1.2, JR3, PR1, PR5, KIN2, and GSH1, and to confer higher seed germination and root growth with high salinity in transgenic Arabidopsis, in addition to enhanced resistance to Ralstonia solanacearum (Jung et al., 2007).

\section{Modifying Transporter Activity for Stress Tolerance}

Plants have developed efficient strategies to maintain ion concentration in the cytoplasm at low levels. Transporters such as $\mathrm{Na}^{+} / \mathrm{H}^{+}$and $\mathrm{K}^{+} / \mathrm{H}^{+}$antiporters (NHXs), sucrose transporters and amino acid transporters have important roles to keep this balance. A group of transporters including NHXs, high affinity 
$\mathrm{K}^{+}$transporters (HKTs), and salt overly sensitive 1 (SOS1) have been shown to maintain intracellular ion and $\mathrm{pH}$ homeostasis, and also contribute to the regulation of a wide variety of physiological processes associated with growth and development (Bassil et al., 2012).

Transgenic barley lines overexpressing a subfamily HKT transporter $(H v H K T 2 ; 1)$ showed improved biomass production under salt stress $(100 \mathrm{mM} \mathrm{NaCl})$ probably through $\mathrm{Na}^{+}$exclusion or accumulation of excessive $\mathrm{Na}^{+}$in the leaves (Mian et al., 2011). The HvNHX2 gene driven by the CaMV 35S promoter was introduced into two cultivars of potato, resulting in improved $\mathrm{NaCl}$ tolerance of one of the cultivars (Bayat et al., 2010). Bayat et al. (2011) also introduced HvNHX2 in Arabidopsis thaliana and showed that transgenic plants grew normally at $200 \mathrm{mM} \mathrm{NaCl}$.

In acid soils, aluminum $\left(\mathrm{Al}^{3+}\right)$ can be toxic for plants. Over expression of the barley HvAACT1 encoding a citrate transporter enhanced the $\mathrm{Al}^{3+}$ tolerance in barley and wheat (Triticum aestivum; Zhou et al., 2013). Besides, Fujii et al. (2012) showed that $1 \mathrm{~kb}$-insertion upstream of the coding region altered expression patterns of $H v A A C T 1$, leading to enhancement of $\mathrm{Al}^{3+}$ tolerance in barley cv. Morex.

Boron toxicity can severely limit crop production worldwide and is best combated by using tolerant varieties. Sutton et al. (2007) demonstrated that increased copy number of Bot 1 encoding a boron efflux transporter is the base of boron-toxicity tolerance in an African barley landrace containing four copies of the gene.

Iron deficiency is a major cause of reduced plant productivity in alkaline soils. Constitutive expression of a barley ironphytosiderophore transporter (HvYS1) in transgenic rice increased iron uptake from alkaline soil (Gómez-Galera et al., 2012).

\section{A Well-Known Success Story: The Hva1 Gene for Drought Tolerance}

LEA proteins are a well-known group of proteins characterized by hydrophilic nature, large size, and high accumulation during seed desiccation and in response to abiotic stresses (BhatnagarMathur et al., 2008). HVA1, a 22kDA group 3 LEA protein expressed in the barley aleurone, is the first characterized and most studied barley LEA protein, having the potential to enhance abiotic stress tolerance through transgenic approaches.

HVA1 expression increased drought tolerance of spring wheat, conferring higher biomass production and water use efficiency under greenhouse drought conditions (Sivamani et al., 2000). Bahieldin et al. (2005) reported improvement in drought tolerance in four independent T4 transgenic lines tested in nine field experiments over six growing seasons, and indicated that the field performance of lines was correlated with the level of HVA1 transgene expression. Constitutive overexpression of HVA1 in rice $\mathrm{cv}$. Nipponbare increased tolerance to water deficit and salinity as shown by delayed damage symptoms and improved recovery (Xu et al., 1996). Further analysis of the T2 generation of these transgenic lines under prolonged drought stress indicated the possibility of better cell membrane protection with HVA1 overexpression (Babu et al., 2004). Similarly, analysis of third generation transgenic rice plants (cv. Pusa Basmati 1) revealed improved cell integrity in transgenic plants under salt and drought stress conditions (Rohila et al., 2002). HVA1 expression by an $\mathrm{ABA} /$ stress-inducible promoter resulted in improved root architecture and better tolerance to osmotic, salt, drought and cold stresses in transgenic rice (Chen et al., 2015). In a recent study, expression of HVA1 in transgenic maize plants conferred survival under strong drought and tolerance to $100-300 \mathrm{mM}$ $\mathrm{NaCl}$ in the T3 generation (Nguyen and Sticklen, 2013). The same group reported that co-expression of HVA1 with E. coli mtlD (mannitol-1-phosphate dehydrogenase) in maize was more effective under drought stress, and capable to enhance shoot and root growth under salt stress when compared to transgenic plants expressing either gene, and underlined the potential of their coexpression for improvement of abiotic stress tolerance (Nguyen et al., 2013).

Transformation of HVA1 into three oat (Avena sativa L.) cultivars resulted in better tolerance to osmotic (salt and mannitol) stresses compared to non-transgenic control plants (Maqbool et al., 2002). Constitutive or stress-inducible HVA1 expression in drought-intolerant creeping bentgrass (Agrostis stolonifera var. palustris) resulted in higher turf quality and lower leaf wilting under water deficiency (Fu et al., 2007). Protection of stability of plasma and chloroplastic membranes under drought and salt stress conditions were observed in mulberry (Morus indica) transformed HVA1 under the constitutive actin1 promoter (Lal et al., 2008). The same transgenic mulberry lines also showed better cold tolerance (Checker et al., 2012). Seedlings of common bean (Phaseolus vulgaris L) transgenic lines expressing HVA1 under the control of the $35 \mathrm{~S}$ promoter displayed enhanced drought tolerance and increased root length (Kwapata et al., 2012).

\section{CONCLUSIONS AND FUTURE PERSPECTIVES}

Abiotic stress tolerant crops will probably be key for food security by helping agriculture to cope with climatic change (IPCC, 2015). Barley can provide a significant source of genes for stress tolerance due to its high diversity and adaptability.

Exploiting TFs in the design of stress tolerant transgenic plants has been proposed as a more effective tool than expressing single genes (Cominelli et al., 2013). In fact, overexpression of barley $H v W R K Y 38, H v D R E B 1, H v S N A C 1$, and $H v C B F 4$ has proven to be very effective in conferring abiotic stress tolerance to other species, and provided tolerance to multiple stresses via both ABA-dependent and -independent pathways (Table 1). Complete functional analyses of barley TFs are still needed to understand regulatory networks related to abiotic stress responses and to reveal the cross-talk between different signaling pathways during stress adaptation.

Single gene transformation, however, can provide good results as indicated by the performance of wheat and rice plants expressing the barley HVA1 LEA protein: in field conditions they have shown improved tolerance to salinity and drought. A less investigated group of genes from barley are membrane transporters that regulate ionic homeostasis in cells, and may have a high potential for creating cultivars with better tolerance to salinity and other mineral toxicities in various crops. 
In conclusion, despite our knowledge toward resolving barley's high survival and adaptability in stressful environment is still limited, several stress tolerance genes have been characterized well enough to move them from basic research to implementation in crops. The wild relatives of barley can be of particular interest (Shavrukov et al., 2010; Uçarlı et al., 2016), by providing a range of allelic variants that could explain the degree of adaptive competence and plasticity of Hordeum and be used in plant breeding efforts for stress tolerance.

\section{REFERENCES}

Adem, G. D., Roy, S. J., Zhou, M., Bowman, J. P., and Shabala, S. (2014). Evaluating contribution of ionic, osmotic and oxidative stress components towards salinity tolerance in barley. BMC Plant Biol. 14:113. doi: 10.1186/1471-2229-14-113

Agarwal, P. K., Agarwal, P., Reddy, M. K., and Sopory, S. K. (2006). Role of DREB transcription factors in abiotic and biotic stress tolerance in plants. Plant Cell Rep. 25, 1263-1274. doi: 10.1007/s00299-006-0204-8

Al Abdallat, A. M., Ayad, J. Y., Abu Elenein, J. M., Al Ajlouni, Z., and Harwood, W. A. (2014). Overexpression of the transcription factor HvSNAC1 improves drought tolerance in barley (Hordeum vulgare L.). Mol. Breed. 33, 401-414. doi: 10.1007/s11032-013-9958-1

Atkinson, N. J., and Urwin, P. E. (2012). The interaction of plant biotic and abiotic stresses: from genes to the field. J. Exp. Bot. 63, 3523-3543. doi: $10.1093 /$ jxb/ers 100

Babu, R. C., Zhang, J., Blum, A., Ho, T. H. D., Wu, R., and Nguyen, H. T. (2004). HVA1, a LEA gene from barley confers dehydration tolerance in transgenic rice (Oryza sativa L.) via cell membrane protection. Plant Sci. 166, 855-862. doi: 10.1016/j.plantsci.2003.11.023

Bahieldin, A., Mahfouz, H. T., Eissa, H. F., Saleh, O. M., Ramadan, A. M., and Ahmed, I. A. (2005). Field evaluation of transgenic wheat plants stably expressing the HVA1 gene for drought tolerance. Physiol. Plant. 123, 421-427. doi: 10.1111/j.1399-3054.2005.00470.x

Bassil, E., Coku, A., and Blumwald, E. (2012). Cellular ion homeostasis: emerging roles of intracellular $\mathrm{NHX} \mathrm{Na}{ }^{+} / \mathrm{H}^{+}$antiporters in plant growth and development. J. Exp. Bot. 63, 5727-5740. doi: 10.1093/jxb/ers250

Bayat, F., Shiran, B., and Belyaev, D. V. (2011). Overexpression of HvNHX2, a vacuolar $\mathrm{Na}^{+} / \mathrm{H}^{+}$antiporter gene from barley, improves salt tolerance in Arabidopsis thaliana. Aust. J. Crop Sci. 5, 428-432. Available online at: http:// apps.webofknowledge.com/full_record.do?product=WOS\&search_mode= GeneralSearch\&qid $=1 \&$ SID $=X 1 B m a S 5 K e U r l n P u G 6 Q$ s\&page $=1 \&$ doc $=5$

Bayat, F., Shiran, B., Belyaev, D. V., Yur'eva, N. O., Sobol'kova, G. I., Alizadeh, H., et al. (2010). Potato plants bearing a vacuolar $\mathrm{Na}^{+} / \mathrm{H}^{+}$antiporter HvNHX2 from barley are characterized by improved salt tolerance. Russ. J. Plant Physiol. 57, 696-706. doi: 10.1134/S1021443710050134

Bedada, G., Westerbergh, A., Müller, T., Galkin, E., Bdolach, E., Moshelion, M., et al. (2014). Transcriptome sequencing of two wild barley (Hordeum spontaneum L.) ecotypes differentially adapted to drought stress reveals ecotype-specific transcripts. BMC Genomics 15:995. doi: 10.1186/1471-2164$15-995$

Bhatnagar-Mathur, P., Vadez, V., and Sharma, K. K. (2008). Transgenic approaches for abiotic stress tolerance in plants: retrospect and prospects. Plant Cell Rep. 27, 411-424. doi: 10.1007/s00299-007-0474-9

Campoli, C., Shtaya, M., Davis, S. J., and von Korff, M. (2012). Expression conservation within the circadian clock of a monocot: natural variation at barley Ppd-H1 affects circadian expression of flowering time genes, but not clock orthologs. BMC Plant Biol. 12:97. doi: 10.1186/1471-2229-12-97

Checker, V. G., Chhibbar, A. K., and Khurana, P. (2012). Stress-inducible expression of barley Hval gene in transgenic mulberry displays enhanced tolerance against drought, salinity and cold stress. Transgenic Res. 21, 939-957. doi: 10.1007/s11248-011-9577-8

Chen, Y. J., Perera, V., Christiansen, M. W., Holme, I. B., Gregersen, P. L., Grant, M. R., et al. (2013). The barley HvNAC6 transcription factor affects ABA

\section{AUTHOR CONTRIBUTIONS}

FG has outlined the idea and wrote the manuscript with ZÖ and CU. DR contributed to critical reading and edition of the manuscript.

\section{ACKNOWLEDGMENTS}

This work was supported by the Scientific Research Projects Coordination Unit of Istanbul University (BAP No. 4712).

accumulation and promotes basal resistance against powdery mildew. Plant Mol. Biol. 83, 577-590. doi: 10.1007/s11103-013-0109-1

Chen, Y. S., Lo, S. F., Sun, P. K., Lu, C. A., Ho, T. H., and Yu, S. M. (2015). A late embryogenesis abundant protein HVAl regulated by an inducible promoter enhances root growth and abiotic stress tolerance in rice without yield penalty. Plant Biotechnol. J. 13, 105-116. doi: 10.1111/pbi.12241

Comadran, J., Kilian, B., Russell, J., Ramsay, L., Stein, N., Ganal, M., et al. (2012). Natural variation in a homolog of Antirrhinum CENTRORADIALIS contributed to spring growth habit and environmental adaptation in cultivated barley. Nat Genet. 44, 1388-1392. doi: 10.1038/ng.2447

Cominelli, E., Conti, L., Tonelli, C., and Galbiati, M. (2013). Challenges and perspectives to improve crop drought and salinity tolerance. New Biotechnol. 30, 355-361. doi: 10.1016/j.nbt.2012.11.001

Fu, D., Huang, B., Xiao, Y., Muthukrishnan, S., and Liang, G. H. (2007). Overexpression of barley hval gene in creeping bentgrass for improving drought tolerance. Plant Cell Rep. 26, 467-477. doi: 10.1007/s00299-006-0258-7

Fujii, M., Yokosho, K., Yamaji, N., Saisho, D., Yamane, M., Takahashi, H., et al. (2012). Acquisition of aluminium tolerance by modification of a single gene in barley. Nat. Commun. 3, 713. doi: 10.1038/ncomms1726

Gómez-Galera, S., Sudhakar, D., Pelacho, A. M., Capell, T., and Christou, P. (2012). Constitutive expression of a barley Fe phytosiderophore transporter increases alkaline soil tolerance and results in iron partitioning between vegetative and storage tissues under stress. Plant Physiol. Biochem. 53, 46-53. doi: 10.1016/j.plaphy.2012.01.009

Guo, P., Baum, M., Grando, S., Ceccarelli, S., Bai, G., Li, R., et al. (2009). Differentially expressed genes between drought-tolerant and drought-sensitive barley genotypes in response to drought stress during the reproductive stage. J. Exp. Bot. 60, 3531-3544. doi: 10.1093/jxb/erp194

Gupta, B., Sengupta, A., Jayita, S., and Gupta, J. (2013). Plant abiotic stress: “omics” approach. J. Plant Biochem. Physiol. 1, 1-2. doi: 10.4172/2329-9029.1000e108

IPCC (2015). Available online at: http://www.ipcc.ch/index.htm

James, V. A., Neibaur, I., and Altpeter, F. (2008). Stress inducible expression of the DREB1A transcription factor from xeric, Hordeum spontaneum L. in turf and forage grass (Paspalum notatum Flugge) enhances abiotic stress tolerance. Transgenic Res.17, 93-104. doi: 10.1007/s11248-007-9086-y

Jeknić, Z., Pillman, K. A., Dhillon, T., Skinner, J. S., Veisz, O., CuestaMarcos, A., et al. (2014). Hv-CBF2A overexpression in barley accelerates $C O R$ gene transcript accumulation and acquisition of freezing tolerance during cold acclimation. Plant Mol. Biol. 84, 67-82. doi: 10.1007/s11103-0130119-z

Jung, J., Won, S. Y., Suh, S. C., Kim, H., Wing, R., Jeong, Y., et al. (2007). The barley ERF-type transcription factor HvRAF confers enhanced pathogen resistance and salt tolerance in Arabidopsis. Planta 225, 575-588. doi: 10.1007/s00425006-0373-2

Kwapata, K., Nguyen, T., and Sticken, M. (2012). Genetic transformation of common bean (Phaseolus vulgaris L.) with the Gus color marker, the Bar herbicide resistance, and the barley (Hordeum vulgare) HVA1 drought tolerance genes. Int. J. Agron. 2012:198960. doi: 10.1155/2012/198960

Lal, S., Gulyani, V., and Khurana, P. (2008). Overexpression of HVA1 gene from barley generates tolerance to salinity and water stress in transgenic mulberry (Morus indica). Transgenic Res. 17, 651-663. doi: 10.1007/s11248-007-9145-4

Li, H., Guo, Q., Lan, X., Zhou, Q., and Wei, N. (2014). Comparative expression analysis of five WRKY genes from Tibetan hulless barley under various abiotic 
stresses between drought-resistant and sensitive genotype. Acta Physiol. Plant. 36, 963-973. doi: 10.1007/s11738-013-1475-7

Li, W. T., Liu, C., Liu, Y. X., Pu, Z. E., Dai, S. F., Wang, J. R., et al. (2013). Metaanalysis of QTL associated with tolerance to abiotic stresses in barley. Euphytica 189, 31-49. doi: 10.1007/s10681-012-0683-3

Mangelsen, E., Kilian, J., Harter, K., Jansson, C., and Sundberg, E. (2011). Transcriptome analysis of high-temperature stress in developing barley caryopses: early stress responses and effects on storage compound biosynthesis. Mol. Plant 4, 97-115. doi: 10.1093/mp/ssq058

Maqbool, B., Zhong, H., El-Maghraby, Y., Ahmad, A., Chai, B., Wang, W., et al. (2002). Competence of oat (Avena sativa L.) shoot apical meristems for integrative transformation, inherited expression, and osmotic tolerance of transgenic lines containing hva1. Theor. Appl. Genet. 105, 201-208. doi: 10.1007/s00122-002-0984-3

McGrann, G. R., Steed, A., Burt, C., Goddard, R., Lachaux, C., Bansal, A., et al. (2015). Contribution of the drought tolerance-related stress-responsive NAC1 transcription factor to resistance of barley to Ramularia leaf spot. Mol. Plant Pathol. 16, 201-219. doi: 10.1111/mpp.12173

Mian, A., Oomen, R. J. F. J., Isayenkov, S., Sentenac, H., Maathuis, F. J. M., and Véry, A. A. (2011). Over-expression of an $\mathrm{Na}+$ - and $\mathrm{K}+$-permeable HKT transporter in barley improves salt tolerance. Plant J. 68, 468-479. doi: 10.1111/j.1365-313X.2011.04701.x

Munns, R., James, R., and Lauchli, A. (2006). Approaches to increasing the salt tolerance of wheat and other cereals. J. Exp. Bot. 57, 1025-1043. doi: $10.1093 /$ jxb/erj100

Nakashima, K., Takasaki, H., Mizoi, J., Shinozaki, K., and Yamaguchi-Shinozaki, K. (2012). NAC transcription factors in plant abiotic stress responses. Biochim. Biophys. Acta. 1819, 97-103. doi: 10.1016/j.bbagrm.2011.10.005

Nguyen, T. X., Nguyen, T., Alameldin, H., Goheen, B., Loescher, W., and Sticklen, M. (2013). Transgene pyramiding of the HVA1 and $\mathrm{mtlD}$ in T3 maize (Zea mays L.) plants confers drought and salt tolerance, along with an increase in crop biomass. Int. J. Agron. 2013, 1-10. doi: 10.1155/2013/598163

Nguyen, T. X., and Sticklen, M. (2013). Barley HVA1 gene confers drought and salt tolerance in transgenic maize (Zea mays L.). Adv. Crop Sci. Tech. 1, 1. doi: 10.4172/2329-8863.1000105

Oh, S. J., Kwon, C. W., Choi, D. W., Song, S. I., and Kim, J. K. (2007). Expression of barley $\mathrm{HvCBF} 4$ enhances tolerance to abiotic stress in transgenic rice. Plant Biotechnol. J. 5, 646-656. doi: 10.1111/j.1467-7652.2007.00272.x

Ozturk, Z. N., Talam, V., Deyholos, M., Michalowski, C. B., Galbraith, D. W., Gozukirmizi, N., et al. (2002). Monitoring large-scale changes in transcript abundance in drought- and salt-stressed barley. Plant Mol. Biol. 48, 551-573. doi: 10.1023/A:1014875215580

Puranik, S., Sahu, P. P., Srivastava, P. S., and Prasad, M. (2012). NAC proteins: regulation and role in stress tolerance. Trends Plant Sci. 17, 369-381. doi: 10.1016/j.tplants.2012.02.004

Rohila, J. S., Jain, R. K., and Wu, R. (2002). Genetic improvement of Basmati rice for salt and drought tolerance by regulated expression of a barley Hval cDNA. Plant Sci. 163, 525-532. doi: 10.1016/S0168-9452(02)00155-3

Rollins, J. A., Habte, E., Templer, S. E., Colby, T., Schmidt, J., and von Korff, M. (2013). Leaf proteome alterations in the context of physiological and morphological responses to drought and heat stress in barley (Hordeum vulgare L.). J. Exp. Bot. 64, 3201-3212. doi: 10.1093/jxb/ert158

Shavrukov, Y., Gupta, N. K., Miyazaki, J., Baho, M. N., Chalmers, K. J., Tester, M., et al. (2010). HvNax3-a locus controlling shoot sodium exclusion derived from wild barley (Hordeum vulgare ssp. spontaneum). Funct. Integr. Genomics 10, 277-291. doi: 10.1007/s10142-009-0153-8

Sicher, R. C., Timlin, D., and Bailey, B. (2012). Responses of growth and primary metabolism of water-stressed barley roots to rehydration. J. Plant Physiol. 169, 686-695. doi: 10.1016/j.jplph.2012.01.002

Singh, D., and Laxmi, A. (2015). Transcriptional regulation of drought response: a tortuous network of transcriptional factors. Front. Plant Sci. 6:895. doi: 10.3389/fpls.2015.00895

Sivamani, E., Bahieldin, A., Wraith, J. M., Al-Niemi, T., Dyer, W. E., Ho, T. H. D., et al. (2000). Improved biomass productivity and water use efficiency under water deficit conditions in transgenic wheat constitutively expressing the barley HVA1 gene. Plant Sci. 155, 1-9. doi: 10.1016/S0168-9452(99)00247-2
Stockinger, E. J., Skinner, J. S., Gardner, K. G., Francia, E., and Pecchioni, N. (2007). Expression levels of barley Cbf genes at the Frost resistance-H2 locus are dependent upon alleles at Fr-H1 and Fr-H2. Plant J. 51, 308-321. doi: 10.1111/j.1365-313X.2007.0141.x

Sutton, T., Baumann, U., Hayes, J., Collins, N. C., Shi, B., Schnurbusch, T., et al. (2007). Boron-toxicity tolerance in transporter amplification. Science 318, 1446-1449. doi: 10.1126/science.1146853

Svensson, J. T., Crosatti, C., Campoli, C., Bassi, R., Stanca, A. M., Close, T. J., et al. (2006). Transcriptome analysis of cold acclimation in barley Albina and Xantha mutants. Plant Physiol. 141, 257-270. doi: 10.1104/pp.105.072645

Tombuloglu, H., Kekec, G., Sakcali, M. S., and Unver, T. (2013). Transcriptomewide identification of R2R3-MYB transcription factors in barley with their boron responsive expression analysis. Mol. Genet. Genomics 288, 141-155. doi: 10.1007/s00438-013-0740-1

Turner, A., Beales, J., Faure, S., Dunford, R. P., and Laurie, D. A. (2005). The pseudo-response regulator Ppd-H1 provides adaptation to photoperiod in barley. Science 310, 1031-1034. doi: 10.1126/science.1117619

Uçarl, C., McGuffin, L. J., Çaputlu, S., Aravena, A., and Gürel, F. (2016). Genetic diversity at the Dhn3 locus in Turkish Hordeum spontaneum populations with comparative structural analyses. Sci. Rep. 6:20966. doi: 10.1038/srep20966

von Zitzewitz, J., Cuesta-Marcos, A., Condon, F., Castro, A. J., Chao, S., Corey, A., et al. (2011). The genetics of winterhardiness in barley: perspectives from genome-wide association mapping. Plant Genome 4, 76-91. doi: 10.3835/plantgenome2010.12.0030

Witzel, K., Weidner, A., Surabhi, G. K., Börner, A., and Mock, H. P. (2009). Salt stress-induced alterations in the root proteome of barley genotypes with contrasting response towards salinity. J. Exp. Bot. 60, 3545-3557. doi: $10.1093 /$ jxb/erp198

Xiong, X., James, V. A., Zhang, H., and Altpeter, F. (2010). Constitutive expression of the barley HvWRKY38 transcription factor enhances drought tolerance in turf and forage grass (Paspalum notatum Flugge). Mol. Breed. 25, 419-432. doi: 10.1007/s11032-009-9341-4

Xu, D., Duan, X., Wang, B., Hong, B., Ho, T., and Wu, R. (1996). Expression of a late embryogenesis abundant protein gene, HVAl, from barley confers tolerance to water deficit and salt stress in transgenic rice. Plant Physiol. 110, $249-257$.

Xu, Z. S., Ni, Z. Y., Li, Z. Y., Li, L. C., Chen, M., Gao, D. Y., et al. (2009). Isolation and functional characterization of HvDREB1-a gene encoding a dehydrationresponsive element binding protein in Hordeum vulgare. J. Plant Res. 122, 121-130. doi: 10.1007/s10265-008-0195-3

Xue, G. P. (2002). An AP2 domain transcription factor HvCBF1 activates expression of cold-responsive genes in barley through interaction with a (G/a)(C/t)CGAC motif. Biochim. Biophys. Acta 1577, 63-72. doi: 10.1016/S0167-4781(02)00410-4

Xue, G. P. (2003). The DNA-binding activity of an AP2 transcriptional activator HvCBF2 involved in regulation of low-temperature responsive genes in barley is modulated by temperature. Plant J. 33, 373-383. doi: 10.1046/j.1365313X.2003.01630.x

Xue, G. P., and Loveridge, C. W. (2004). HvDRF1 is involved in abscisic acid-mediated gene regulation in barley and produces two forms of AP2 transcriptional activators, interacting preferably with a CT-rich element. Plant J. 37, 326-339. doi: 10.1046/j.1365-313X.2003.01963.x

Zhou, G., Delhaize, E., Zhou, M., and Ryan, P. R. (2013). The barley MATE gene, HvAACT1, increases citrate efflux and $\mathrm{Al} 3$ tolerance when expressed in wheat and barley. Ann. Bot. 112, 603-612. doi: 10.1093/aob/mct135

Conflict of Interest Statement: The authors declare that the research was conducted in the absence of any commercial or financial relationships that could be construed as a potential conflict of interest.

Copyright $\odot 2016$ Gürel, Öztürk, Uçarlı and Rosellini. This is an open-access article distributed under the terms of the Creative Commons Attribution License (CC BY). The use, distribution or reproduction in other forums is permitted, provided the original author(s) or licensor are credited and that the original publication in this journal is cited, in accordance with accepted academic practice. No use, distribution or reproduction is permitted which does not comply with these terms. 